\title{
Vitamin D deficiency in an Italian cohort of infertile women
}

\author{
Paola Triggianese $^{1}$ (D) | Abdulla Watad ${ }^{2,3,4}$ | Francesca Cedola ${ }^{1}$ | Carlo Perricone ${ }^{5}$ | \\ Howard Amital $^{2,3,4}$ | Ilio Giambini ${ }^{6}$ | Roberto Perricone ${ }^{1}$ | Yehuda Shoenfeld ${ }^{2,3}$ | \\ Caterina De Carolis ${ }^{7}$
}

\author{
${ }^{1}$ Rheumatology, Allergology and Clinical \\ Immunology, Department of "Medicina dei \\ Sistemi", University of Rome Tor Vergata, \\ Rome, Italy \\ ${ }^{2}$ Department of Medicine 'B', Tel-Aviv \\ University, Tel-Aviv, Israel \\ ${ }^{3}$ Zabludowicz center for Autoimmune \\ Diseases, Tel-Aviv University, Tel-Aviv, Israel \\ ${ }^{4}$ Sackler Faculty of Medicine, Tel-Aviv \\ University, Tel-Aviv, Israel \\ ${ }^{5}$ Reumatologia, Dipartimento di Medicina \\ Interna e Specialità Mediche, Sapienza \\ Università di Roma, Rome, Italy \\ ${ }^{6}$ Department of Laboratory Medicine, Tor \\ Vergata University Hospital of Rome, Rome, Italy \\ ${ }^{7}$ Polymedical Center for Prevention of \\ Recurrent Spontaneous Abortion, Rome, Italy

\section{Correspondence} \\ Paola Triggianese, Rheumatology, Allergology \\ and Clinical Immunology, Department of \\ "Medicina dei Sistemi", University of Rome Tor \\ Vergata, Rome, Italy. \\ Email: triggianese@med.uniroma2.it
}

Problem: The purpose of this study was to explore whether vitamin D might be a marker of female primary infertility in association with the presence of autoimmune diseases (ADs).

Methods: The study was a cross-sectional descriptive study in consecutive outpatients of the Polymedical Center for Prevention of Recurrent Spontaneous Abortion (RSA), in Rome, Italy. Women were eligible if they received a diagnosis of primary infertility or RSA. Serum vitamin D, calcium, and PTH were analyzed.

Results: Women with primary infertility $(n=70)$ or RSA/non-infertile $(n=105)$ were enrolled; controls $(n=250)$ were included. Infertile women presented lower vitamin D $(P=0.03)$ and higher prevalence of $\operatorname{AD}(P=0.007)$ than non-infertile women. In the multivariate analysis, the presence of ADs is associated with higher odds of infertility $(\mathrm{OR}=2.2)$, while normal vitamin $\mathrm{D}$ was a protective factor $(\mathrm{OR}=0.9)$.

Conclusion: We described that having vitamin $D$ deficiency and suffering from an AD are independent risk factors for women primary infertility. Supplementation of vitamin D might be useful for pregnancy outcome.

\section{KEYWORDS}

autoimmunity, infertility, recurrent abortions, thyroid, vitamin D

\section{1 | INTRODUCTION}

Infertility is a common condition that affects $9 \%-18 \%$ of the general population, representing a complex disorder with medical, psychological, and economic aspects. ${ }^{1,2}$ According to the Practice Committee of the American Society for Reproductive Medicine, infertility is defined as the inability to conceive a child after 12 months of regular sexual intercourse, without contraception, in couples who have never had a child. Recurrent spontaneous abortion (RSA) is defined by the occurrence of two or more consecutive failed pregnancies. ${ }^{3}$ The causes of female infertility are different and include genetic and anatomic abnormalities as well as endocrine and autoimmune disorders (ADs). ${ }^{3-6}$ However, unexplained etiology for female infertility accounts for almost $50 \%$ of the infertile conditions. ${ }^{7,8}$ It is believed that a significant proportion of unexplained reproductive failure can be either directly or indirectly related

Paola Triggianese and Abdulla Watad contributed equally to this work. to autoimmunity. ${ }^{9}$ Evidence from the literature extensively reported the presence of autoimmunity among women with infertility/RSA. ${ }^{10-13}$ Immune abnormalities such as the imbalance in natural killer cell (NK) levels and $\mathrm{Th}_{1} / \mathrm{Th}_{2}$ ratio have been associated with RSA. ${ }^{14-17}$

Vitamin $\mathrm{D}$ is a steroid hormone that, in addition to its actions on calcium and bone metabolism, exhibits a plethora of regulatory effects on immune cells. ${ }^{18}$ Active vitamin $\mathrm{D}$ can work as a positive immunomodulator on both the innate and adaptive immune responses. ${ }^{19}$ Hypovitaminosis D is highly prevalent in ADs and correlates with disease activity and comorbidities. ${ }^{19}$ Low levels of vitamin D were also associated with increased risk of pregnancy complications such as gestational diabetes, pre-eclampsia, and fetus growth abnormality. ${ }^{17}$ Recent data from retrospective and prospective trials have demonstrated contradictive results concerning the role of vitamin $D$ in female reproduction and in vitro fertilization outcome. ${ }^{20}$ In this view, the supplementation of vitamin $\mathrm{D}$ might be useful in women with reproductive failure and it is under investigation. ${ }^{17}$ Serum vitamin D (25[OH]D) level 
is recognized as the best indicator of vitamin $D$ status. The purpose of this study was to explore whether $25(\mathrm{OH}) \mathrm{D}$ levels might be a marker of female primary infertility in association with the presence of ADs.

\section{2 | MATERIALS AND METHODS}

The study was designed as a cross-sectional descriptive study in consecutive outpatients of the Polymedical Center for Prevention of RSA, San Giovanni Addolorata Hospital in Rome, Italy (time frame 20132015). Women were eligible for the study if they received a diagnosis of primary infertility or RSA. ${ }^{3}$ The study population was consecutively enrolled over a period of 2 years. Among 250 women involved as possible candidate, 75 were excluded due to female factors in about $35 \%$ of cases, to male factors in $30 \%$ of cases, and to both female and male factors in $35 \%$ of cases. Additional exclusion criteria were as follows: medical history of (i) bone mineral metabolic disease, (ii) liver disease, and (iii) kidney dysfunction. Thus, 175 women with a history of primary infertility or RSA were enrolled in the study. Women with primary infertility $(n=70)$ showed a mean infertility duration of $3 \pm 1.5$ years, while RSA women $(n=105)$ experienced two or more consecutive spontaneous abortions prior to the $20^{\circ}$ gestational week. ${ }^{3}$ At the time of the enrollment, all women were not pregnant and were not on vitamin D supplementation. Data on endocrine diseases as well as concurrent ADs were collected. In the whole study population, we reported cases of autoimmune thyroid diseases (ATD), including patients with positivity for antithyroid peroxidase and/or antithyroglobulin antibodies: Women with clinical thyroid dysfunction were excluded as were under treatment with levothyroxine or antithyroid drugs. ${ }^{6}$ Moreover, we registered cases of systemic lupus erythematosus (SLE), antiphospholipid syndrome (APS), rheumatoid arthritis, and connective tissue diseases, diagnosed according to the published criteria. ${ }^{4,7,9}$ All patients underwent laboratory examination for screening $25(\mathrm{OH})$ $\mathrm{D}$, calcium, and parathormone (PTH) serum levels. A control group included women $(n=250)$ who were age-matched with both infertile and non-infertile women. Women who served as controls referred to the Department of Laboratory Medicine (Tor Vergata University Hospital of Rome, Italy) for common laboratory investigations.

The study protocol was approved by the local ethics committee. Informed consents were obtained from the women before they entered the study. The study was conducted in accordance with the ethical principles of the Declaration of Helsinki and was consistent with the guidelines for good clinical practice.

\section{1 | Laboratory assays}

All the women in the study underwent calcium, PTH, and $25(\mathrm{OH}) \mathrm{D}$ serum levels testing as part of their medical care. Women agreed to perform the panel in a context of an evaluation before conception. The venous blood (fasting) was collected under aseptic conditions, and the serum was used for the analysis of calcium, PTH, and 25(OH)D using routine laboratory techniques. Reference ranges were 8.4-10.2 mg/dL for serum calcium and $14-72 \mathrm{pg} / \mathrm{mL}$ for plasma intact $\mathrm{PTH} ; 25(\mathrm{OH})$
D status was graded as deficiency $(<20 \mathrm{ng} / \mathrm{mL})$ and severe deficiency $(<7 \mathrm{ng} / \mathrm{mL})$ based on 2011 Endocrine Society guidelines. ${ }^{21}$ Serum insulin and glucose levels were also measured to assess the HOMA (Homeostasis Model Assessment) index (Insulin $[\mathrm{mU} / \mathrm{mL}] \times$ Glucose $[\mathrm{mmol} / \mathrm{l}]) / 22.5$ : Values $<2.7$ were considered negative. ${ }^{6,7}$ Body mass index (BMI, $\mathrm{kg} / \mathrm{m}^{2}$ ) was also measured.

Controls were used for their vitamin D serum levels, while laboratory reference range values were used for the "normal values" of calcium and PTH.

\subsection{Statistics}

Continuous variables are presented as means \pm standard deviations. Before commencing statistical processing, the normality of distribution was checked with the D'Agostino-Pearson omnibus test. Normally distributed and non-normally distributed variables were compared using an independent $t$ test and Mann-Whitney $U$ test, respectively. Chi-square or Fisher's exact test was utilized for proportion comparisons. A multivariate logistic regression was carried out, correcting for confounding factors. Odds ratio (OR) was used to have a measure of association between the exposure to the variable of interest (eg, vitamin $D, A D s$ ) and the outcome (infertility). $P$-values $<0.05$ were considered statistically significant. All data were stored on a server, and statistical analyses were performed using SPSS Statistics version 21.0

\section{3 | RESULTS}

One hundred and seventy-five women were recruited. In this study, RSA women were considered as non-infertile women as all of them experienced the beginning of pregnancy.

Demographic data of women in the study population are summarized in Table 1.

\section{1 | Vitamin D levels}

Mean serum 25(OH)D resulted lower in infertile women $(21.88 \pm 9.79)$ than in both non-infertile women $(25.74 \pm 11.17, P=0.03)$ and controls (25.6 $\pm 9.3, P=0.01$ ), while no differences occurred between non-infertile women and controls (Figure 1A, Table 1). Mean calcium and PTH levels were in the reference range in both infertile and non-infertile groups (Table 1).

A vitamin $D$ deficiency ( $<20 \mathrm{ng} / \mathrm{mL}$ ) was present in a higher prevalence in the infertile group $(45.7 \%, 32 / 70)$ than in the non-infertile one $(30.4 \%, 32 / 105, P=0.04)$ and in controls $(27.2 \%, 68 / 250, P=0.003)$ (Figure 1B). In these latest groups, two infertile women and one noninfertile woman showed a severe deficiency of $25(\mathrm{OH}) \mathrm{D}(<7 \mathrm{ng} / \mathrm{mL})$. None of the controls had a severe deficiency of $25(\mathrm{OH}) \mathrm{D}$.

\subsection{Autoimmune diseases}

In the whole study population, 65 of 175 women were affected by one AD with $69.2 \%(45 / 65)$ ATD (Table 2). Infertile women showed a 
TABLE 1 Data from the study groups

\begin{tabular}{lclll} 
Parameter & $\begin{array}{l}\text { Infertile group } \\
(\mathrm{n}=70)\end{array}$ & $\begin{array}{l}\text { Non-infertile } \\
\text { group }(\mathrm{n}=105)\end{array}$ & $\begin{array}{l}\text { Controls } \\
(\mathrm{n}=250)\end{array}$ & $\begin{array}{l}\text { Statistical } \\
\text { significance }\end{array}$ \\
\hline Age $(\mathrm{y})$ & $37.57 \pm 4.35$ & $37.01 \pm 4.33$ & $35.6 \pm 4.8$ & N.S. \\
\hline BMI $\left(\mathrm{kg} / \mathrm{m}^{2}\right)$ & $22 \pm 1$ & $22.5 \pm 1$ & N.A. & N.S. \\
\hline HOMA index & $<2.7$ & $<2.7$ & N.A. & - \\
\hline $25(\mathrm{OH}) \mathrm{D}(\mathrm{ng} / \mathrm{mL})$ & $21.88 \pm 9.79^{*}$ & $25.74 \pm 11.17$ & $25.6 \pm 9.3$ & $*<0.05$ \\
\hline PTH $(\mathrm{pg} / \mathrm{mL})$ & $43.65 \pm 17.67$ & $44.34 \pm 22.48$ & N.A. & N.S. \\
\hline Calcium $(\mathrm{mg} / \mathrm{dL})$ & $8.10 \pm 2.36$ & $6.28 \pm 4.22$ & N.A. & N.S. \\
\hline
\end{tabular}

BMI, body mass index; HOMA, Homeostasis Model Assessment; 25(OH)D, 25 hydroxyvitamin D; PTH, parathormone; N.S, not significant; N.A, not applicable.

Data are expressed as mean \pm standard deviation. Variables were compared using an independent $t$ test $(P$-value $<0.05$ was considered significant.

*infertile vs non-infertile women, $P=0.03$, infertile women vs controls, $P=0.01$ ).

higher prevalence of ADs with respect to non-infertile women $(52.8 \%$ vs $27.6 \%, P=0.0004$, Figure $2 A$ ). In addition, ATD was prevalent in infertile group (38.6\%) more than in non-infertile (17\%, $P=0.0015$, Figure 2B). ATD women had no significant lower 25(OH)D levels than non-ATD women, in both the infertile and the non-infertile groups. In the whole population, all AD women had lower serum 25(OH)D than no AD women ( $P=0.04$, Figure 3 ). This difference in $25(\mathrm{OH}) \mathrm{D}$ between women with $A D$ and women without $A D$ was not confirmed when women were considered distinctly in accordance with the fertility status (infertile/non-infertile).

Among the other ADs (20/65) in the whole population, we registered nine women with APS (all of them were in non-infertile group), four women with rheumatoid arthritis (75\% in infertile group), six women with connective tissue diseases (83.3\% in infertile group), and one woman with SLE (non-infertile woman) (Table 2).

\section{3 | Univariate and multivariate analyses}

The univariate analysis confirmed that the infertile group presented lower 25(OH)D levels and a higher prevalence of ADs than the noninfertile group ( $P=0.03$ and $P=0.007$, respectively). At the multivariate logistic regression analysis, the presence of $A D$ s and lower $25(\mathrm{OH})$ $D$ levels was found to be independently associated with female infertility. The presence of at least one AD yielded an OR of 2.22 [95\% confidence interval $(\mathrm{Cl})=1.01-4.89, P=0.047$ ], while higher $25(\mathrm{OH}) \mathrm{D}$ levels found to be protective factor for female primary infertility with an OR of $0.96(95 \% \mathrm{Cl}=0.92-0.99, P=0.041$, Table 3$)$.

\section{4 | DISCUSSION}

Although infertility among women is a multifactorial condition and might be attributed to various causes, including genetic, autoimmune, and non-autoimmune factors, in $50 \%$ of cases, the clear etiology is

TABLE 2 Autoimmune diseases in the study population

\begin{tabular}{|llr}
\hline Whole population & Overall prevalence N (\%) & $65(37.1)$ \\
& ATD N (\%) & $45 / 65(69.2)$ \\
& Other N (\%) & $20 / 65(30.8)$ \\
\hline Infertile group & Overall prevalence N (\%) & $37 / 70(52.8)^{*}$ \\
& ATD N (\%) & $27 / 70(38.6)^{* *}$ \\
Non-infertile & Other N (\%) & $10 / 70(14.3)$ \\
group & Overall prevalence N (\%) & $28 / 105(26.7)^{*}$ \\
& ATD N (\%) & $18 / 105(17.14)^{* *}$ \\
& Other N (\%) & $10 / 105(9.5)$ \\
\hline
\end{tabular}

ATD, autoimmune thyroid diseases; Other, other autoimmune conditions (systemic lupus erythematosus, antiphospholipid syndrome, rheumatoid arthritis, and connective tissue diseases). Chi-square test was utilized for proportion comparisons $\left({ }^{*} P=0.0004 ;{ }^{* *} P=0.0015\right)$.
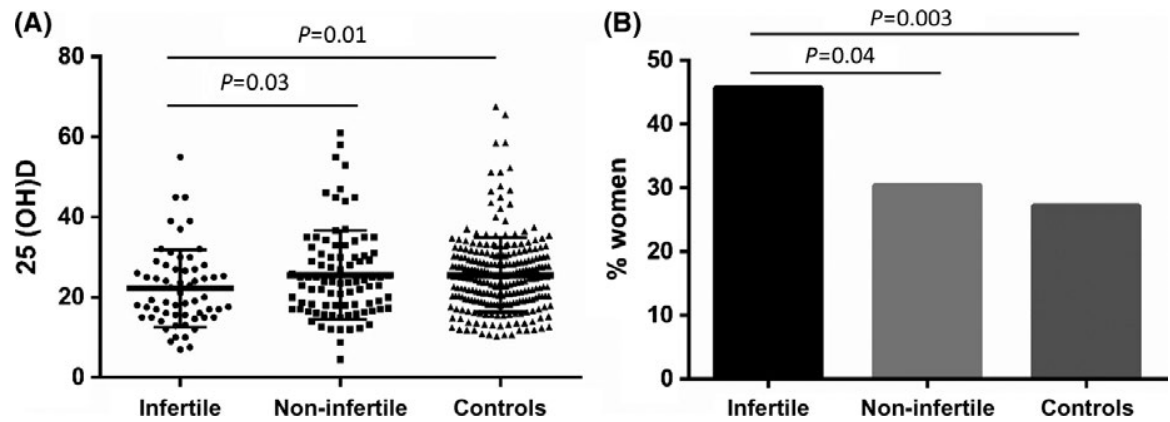

FIGURE 1 Vitamin D in the study groups. Panel A. Mean serum vitamin D (25[OH]D) resulted lower in infertile women than in non-infertile women $(P=0.03)$ and in controls $(P=0.01)$. Variables were compared using an independent $t$ test. Panel B. Prevalence of vitamin $D$ deficiency $(<20 \mathrm{ng} / \mathrm{mL})$ was higher in infertile women than in non-infertile $(P=0.04)$ and controls $(P=0.003)$. Chi-square test was utilized for proportion comparisons 

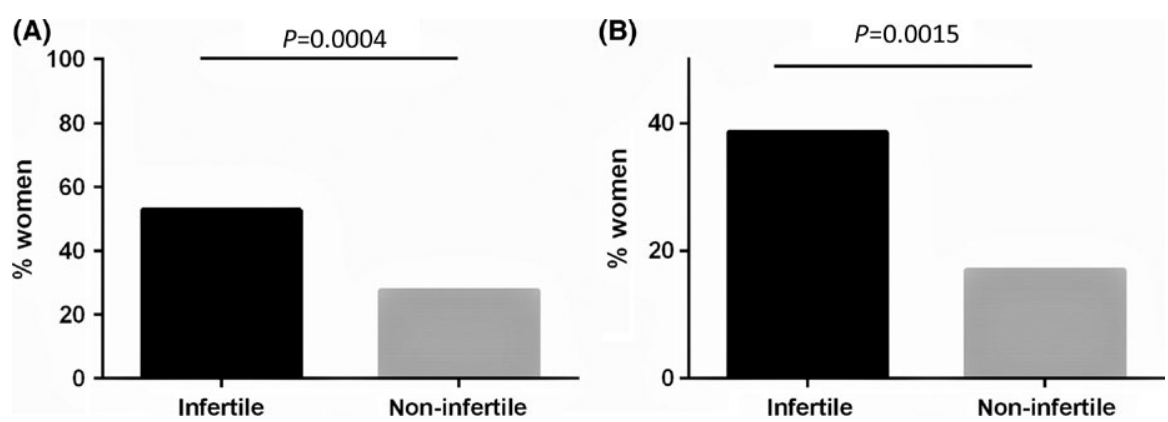

FIGURE 2 Autoimmune diseases in the study groups. Panel A. Infertile women showed a higher prevalence of autoimmune diseases (ADs) with the respect to noninfertile women $(P=0.0004)$. Panel B. The prevalence of autoimmune thyroid diseases was higher in infertile than in non-infertile women $(P=0.0015)$. Chi-square test was utilized for proportion comparisons

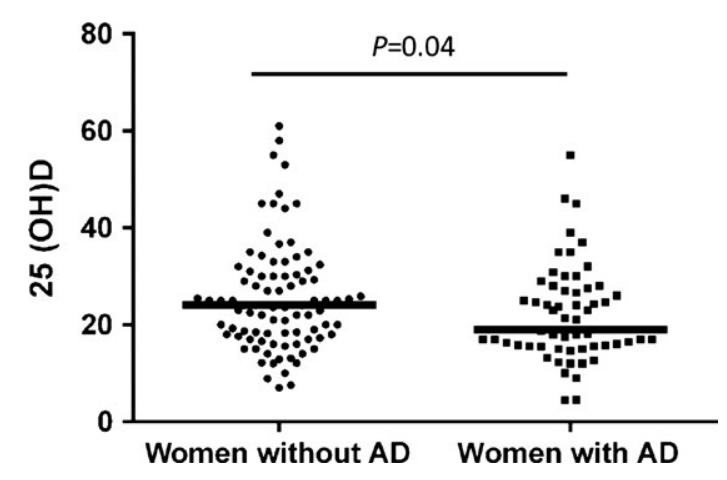

FIGURE 3 Vitamin D levels in accordance with the presence of autoimmune diseases. In the whole population, women with autoimmune diseases (ADs) had lower mean serum vitamin $D$ $(25[\mathrm{OH}] \mathrm{D})$ than women without $\mathrm{ADs}(P=0.04)$. Variables were compared using an independent $t$ test

unknown. ${ }^{3-6}$ However, among conditions of infertility in which the etiology resulted not clear, an increased frequency of abnormalities in immune system has been reported repeatedly. ${ }^{16,17,22,23}$ Interestingly, we have described for the first time that a deficiency in vitamin $D$ levels was prevalent in women with primary infertility with respect to non-infertile women and controls. In this study, we decided to consider women with primary infertility as "infertile" women (without spontaneous abortion and/or living child), while women with RSA were considered as "non-infertile" women because they experienced pregnancies, spontaneous abortion, and/or living child. In the context of the primary infertility, it is possible that the vitamin D deficiency represents a potential clue of immune system dysregulation, in accordance with evidence linking vitamin D deficiency and immune system imbalance. ${ }^{10,18,19}$ Very low vitamin D levels may thus characterize women with primary infertility according to "autoimmune mechanisms" of the pregnancy failure. ${ }^{23}$ Similar results were reported by Al-Jaroudi et $a l,{ }^{24}$ showing a significant higher degree of vitamin $\mathrm{D}$ deficiency in subfertile women in comparison with controls. Pagliardini et al. ${ }^{25}$ evaluated vitamin $\mathrm{D}$ levels among women requiring medical advice concerning infertility, and levels below $30 \mathrm{ng} / \mathrm{mL}$ for $89 \%$ of the entire year were observed. Moreover, in women who underwent an assisted reproduction technologies, vitamin D levels were positively related to the fertilization rate. ${ }^{26}$ Although most of studies support the link between low levels of vitamin D and infertility, a Brazilian study has showed different results, reporting higher prevalence of vitamin D deficiency among women of reproductive age, regardless of their fertility status. ${ }^{27}$ In another study, vitamin D levels were not associated with pregnancy outcome and did not predict the likelihood of the blastocysts implantation in women that went through euploid embryo transfer. ${ }^{28}$ The role of vitamin $\mathrm{D}$ in fertility is not only reinforced by clinical and epidemiological studies but also reinforced by animal models as well. In an animal model study, female rats were divided into two groups, vitamin D-deficient and vitamin D-replete diets. ${ }^{22}$ Among those with vitamin $D$ deficiency, the reproductive capacity and fertility were significantly reduced in comparison to females with normal vitamin D levels regardless the calcium levels. ${ }^{22}$ Immunoregulatory effects of vitamin $\mathrm{D}$ have been reported not only on $\mathrm{T}$ cells but also on innate immune cells. ${ }^{29}$ Data from retrospective and prospective trials have demonstrated contradictive results concerning the role of vitamin D in female reproduction and in vitro fertilization (IVF) outcome. ${ }^{20}$ In this view, the supplementation of vitamin D might be useful in women with reproductive failure and it is under investigation. ${ }^{17}$ Low levels of vitamin $D$ have been reported extensively to be associated with ADs. ${ }^{18,19}$ In our study, however, low levels of vitamin D were found to

\begin{tabular}{|c|c|c|c|c|c|c|}
\hline Variable & Coefficient & SE & $\begin{array}{l}\text { Wald } \\
\text { coefficient }\end{array}$ & $P$-value & OR & $95 \% \mathrm{Cl}$ \\
\hline Age & 0.07 & 0.05 & 2.06 & 0.151 & 1.07 & $0.98-1.17$ \\
\hline $\begin{array}{l}\text { Autoimmune Diseases } \\
\text { (yes vs not) }\end{array}$ & 0.80 & 0.40 & 3.96 & $0.047^{*}$ & 2.22 & $1.01-4.89$ \\
\hline PTH levels & -0.00 & 0.01 & 0.02 & 0.876 & 1.00 & $0.98-1.02$ \\
\hline $25(\mathrm{OH}) \mathrm{D}$ levels & -0.04 & 0.02 & 4.17 & $0.041^{*}$ & 0.96 & $0.92-0.99$ \\
\hline Constant & -1.83 & 1.84 & 0.99 & 0.321 & & \\
\hline
\end{tabular}

TABLE 3 Multivariate logistic regression analysis showing the association between the investigated variables and infertility

$\mathrm{Cl}$, confidence interval; OR, odds ratio; PTH, parathyroid hormone $(\mathrm{pg} / \mathrm{mL}) ; 25(\mathrm{OH}) \mathrm{D}, 25$ hydroxyvita$\min \mathrm{D}(\mathrm{ng} / \mathrm{mL})$.

*Statistically significant with $P<0.05$. 
be independently associated with infertility as found by multivariate analysis regardless the presence of ADs (Table 3).

Women with some ADs including SLE, APS, and ATD are at increased risk of infertility. ${ }^{13,19,23,30}$ In our study, we found that the presence of an $A D$ is significantly associated with primary infertility in the univariate and multivariate analyses as well. The population of our study included a heterogeneous group of ADs but the highest prevalence was registered for the ATD. Assuming that infertile women have an overactive immune system, an increased prevalence of thyroid abnormalities could be expected mainly in terms of autoimmunity. ${ }^{12,31}$ The meaning of these interesting findings was in accordance with the evidence supporting the role of thyroid function in the pathogenesis of many autoimmune disorders even in the absence of defined thyroid autoimmunity. ${ }^{7,12,16,31,32}$ A satisfactory evidence suggests that women with infertility are more likely to have positive antithyroid antibodies than age-matched women who are not infertile, even if euthyroid. ${ }^{33}$ In addition, the prevalence of antithyroid antibodies may be higher in women with polycystic ovarian syndrome (PCOS) than in age-matched controls. ${ }^{34}$ Among infertile women with PCOS, the presence of antithyroid antibodies has been associated with a decreased likelihood of developing ovarian follicles in response to treatment with clomiphene citrate. $^{35}$ It has been suggested that the association between ATD and pregnancy outcome may be independent of that of non-organ-specific autoimmunity. The lower success rate of pregnancy in the patients with thyroid autoimmunity, even if also positive for antiphospholipid, further supports this hypothesis. ${ }^{13}$

Antiphospholipid syndrome is one of the most investigated ADs among infertile women and/or with reduced pregnancy outcome..$^{8,11,36-38}$ It can affect the obstetric outcome through various putative mechanisms, including the disruption of the feto-maternal circulation, and affect the cell division during embryogenesis and the normal function of the trophoblast. ${ }^{11,36,39}$

Systemic lupus erythematosus was also associated with infertility and worse prognosis in cases of SLE patients undergoing assisted reproductive techniques for pregnancy rate. ${ }^{40}$ Additionally, higher prevalence of SLE diagnosis has been found in infertile women. ${ }^{41}$ Menstrual irregularity is present in $53 \%$ of SLE cases under 40 years of age, and this was also associated with SLE disease activity. The function of the ovarian may be also altered in patients with SLE, leading to a decrease in the number of the ovarian reserve. ${ }^{42}$

Finally, our results support the link between autoimmunity and reduced reproductive capacity and suggest that the presence of any $A D$ might affect negatively the fertility status. In our study, we did not find a significant difference of the calcium or PTH levels between infertile and non-infertile women. There are very few studies to evaluate directly the role of calcium in infertility, while, to the best of our knowledge, there are no studies to support the link between PTH levels and female infertility. ${ }^{43,44}$ Therefore, it seems that vitamin D has a dominant role in the reproductive capacity of the female rather than calcium or PTH. Although the $95 \%$ confidence intervals $(\mathrm{Cl})$ of both factors, presence of $A D$ and low levels of vitamin $D$, were close to one, the $P$-value was significant, and both ranges of the $\mathrm{Cl}$ were less than one for vitamin $D$ levels and higher than one for the presence of $A D$ reducing the probability of reproducibility of these results in another population. Nonetheless, while our study has several strengths including its epidemiological and biostatistical design, the retrospective analysis does not allow to draw definite conclusions on the causal relationship between vitamin D and infertility. In addition, our results are expressed in terms of means concerning the aforementioned whole populations rather than in terms of comparisons between subgroups of patients with the specific reported risk factors. A subanalysis of different subpopulations is, here, not performed in accordance with the small sample size of the considered subcohorts of women. Future studies involving larger subpopulations could provide further results.

\section{CONCLUSION}

$A D s$ and low vitamin $D$ levels are both independent risk factors for primary infertility in women. Therefore, vitamin D supplementation may be useful for improving reproductive outcomes in women suffering from primary infertility, in particular for those with concurrent ADs. However, further studies are needed to provide a clear evidentiary basis for this hypothesis.

\section{ACKNOWLEDGMENTS}

None.

\section{REFERENCES}

1. Talmor A, Dunphy B. Female obesity and infertility. Best Pract Res Clin Obstet Gynaecol. 2015;29:498-506.

2. Aghajanova L, Hoffman J, Mok-Lin E, Herndon CN. Obstetrics and gynecology residency and fertility needs: national survey results. Reprod Sci. 2017;24:428-434.

3. Practice Committee of the American Society for Reproductive. Medicine: evaluation and treatment of recurrent pregnancy loss: a committee opinion. Fertil Steril. 2012;98:1103-1111.

4. Chighizola CB, de Jesus GR, Branch DW. The hidden world of anti-phospholipid antibodies and female infertility: a literature appraisal. Autoimmun Rev. 2016;15:493-500.

5. Tsevat DG, Wiesenfeld HC, Parks C, Peipert JF. Sexually transmitted diseases and infertility. Am J Obstet Gynecol. 2017;216:1-9.

6. Triggianese P, Perricone C, Perricone R, De Carolis C. Prolactin and natural killer cells: evaluating the neuroendocrine-immune axis in women with primary infertility and recurrent spontaneous abortion. Am J Reprod Immunol. 2015;73:56-65.

7. Dal Lago A, Vaquero E, Pasqualetti P, Lazzarin N, De Carolis C, Perricone R, Moretti C. Prediction of early pregnancy maternal thyroid impairment in women affected with unexplained recurrent miscarriage. Hum Reprod. 2011;26:1324-1330.

8. Ford HB, Schust DJ. Recurrent pregnancy loss: etiology, diagnosis, and therapy. Rev Obstet Gynecol. 2009;2:76-83.

9. Østensen M, Andreoli L, Brucato A, Cetin I, Chambers C, Clowse ME, Costedoat-Chalumeau N, Cutolo M, Dolhain R, Fenstad MH, Förger F, Wahren-Herlenius M, Ruiz-Irastorza G, Koksvik H, Nelson-Piercy C, Shoenfeld Y, Tincani A, Villiger PM, Wallenius M, von Wolff M. State of the art: reproduction and pregnancy in rheumatic diseases. Autoimmun Rev. 2015;14:376-386.

10. Kwak-Kim J, Skariah A, Wu L, Salazar D, Sung N, Ota K. Humoral and cellular autoimmunity in women with recurrent pregnancy losses 
and repeated implantation failures: a possible role of vitamin D. Autoimmun Rev. 2016;15:943-947.

11. Pengo V, Bison E, Zoppellaro G, Padayattil Jose S, Denas G, Hoxha A, Ruffatti A, Banzato A. APS - Diagnostics and challenges for the future. Autoimmun Rev. 2016;15:1031-1033.

12. Matalon ST, Blank M, Ornoy A, Shoenfeld Y. The association between anti-thyroid antibodies and pregnancy loss. Am J Reprod Immunol. 2001;45:72-77.

13. De Carolis C, Greco E, Guarino MD, Perricone C, Dal Lago A, Giacomelli R, Fontana L, Perricone R. Anti-thyroid antibodies and antiphospholipid syndrome: evidence of reduced fecundity and poor pregnancy outcome in recurrent spontaneous aborters. Am J Reprod Immunol. 2004;52:263-266.

14. Shoenfeld Y, Carp HJ, Molina V, Blank M, Cervera R, Balasch J, Tincani A, Faden D, Lojacono A, Doria A, Konova E, Meroni PL. Autoantibodies and prediction of reproductive failure. Am J Reprod Immunol. 2006;56:337-344.

15. De Carolis C, Perricone C, Perricone R. NK cells, autoantibodies, and immunologic infertility: a complex interplay. Clin Rev Allergy Immunol. 2010;39:166-175.

16. Triggianese $\mathrm{P}$, Perricone $\mathrm{C}$, Conigliaro $\mathrm{P}$, Chimenti MS, Perricone R, De Carolis C. Peripheral blood natural killer cells and mild thyroid abnormalities in women with reproductive failure. Int J Immunopathol Pharmacol. 2016;29:65-75.

17. Triggianese P, Perricone C, Chimenti MS, De Carolis C, Perricone R. Innate immune system at the maternal-fetal interface: mechanisms of disease and targets of therapy in pregnancy syndromes. Am J Reprod Immunol. 2016;76:245-257.

18. Orbach H, Zandman-Goddard G, Amital H, Barak V, Szekanecz Z, Szucs G, Danko K, Nagy E, Csepany T, Carvalho JF, Doria A, Shoenfeld $Y$. Novel biomarkers in autoimmune diseases: prolactin, ferritin, vitamin D, and TPA levels in autoimmune diseases. Ann NY Acad Sci. 2007;1109:385-400.

19. Perricone C, Agmon-Levin N, Colafrancesco S, Shoenfeld Y. Vitamins and systemic lupus erythematosus: to D or not to D. Expert Rev Clin Immunol. 2013;9:397-399.

20. Paffoni A, Ferrari S, Viganò P, Pagliardini L, Papaleo E, Candiani M, Tirelli A, Fedele L, Somigliana E. Vitamin D deficiency and infertility: insights from in vitro fertilization cycles. J Clin Endocrinol Metab. 2014;99:E2372-E2376.

21. Holick MF, Binkley NC, Bischoff-Ferrari HA, Gordon CM, Hanley DA, Heaney RP, Murad MH, Weaver CM, Endocrine Society. Evaluation, treatment, and prevention of vitamin D deficiency: an Endocrine Society clinical practice guideline. J Clin Endocrinol Metab. 2011;96:1911-1930.

22. Kwiecinksi GG, Petrie GI, DeLuca HF. 1,25-Dihydroxyvitamin D3 restores fertility of vitamin D-deficient female rats. Am J Physiol. 1989;256(4 Pt 1):E483-E487.

23. Carp HJ, Selmi C, Shoenfeld Y. The autoimmune bases of infertility and pregnancy loss. J Autoimmun. 2012;38:J266-J274.

24. Al-Jaroudi D, Al-Banyan N, Aljohani NJ, Kaddour O, Al-Tannir M. Vitamin D deficiency among subfertile women: case-control study. Gynecol Endocrinol. 2016;32:272-275.

25. Pagliardini L, Vigano' P, Molgora M, Persico P, Salonia A, Vailati SH, Paffoni A, Somigliana E, Papaleo E, Candiani M. High prevalence of vitamin d deficiency in infertile women referring for assisted reproduction. Nutrients. 2015;7:9972-9984.

26. Abadia L, Gaskins AJ, Chiu YH, Williams PL, Keller M, Wright DL, Souter I, Hauser R. Chavarro JE; Environment and Reproductive Health Study Team. Serum 25-hydroxyvitamin D concentrations and treatment outcomes of women undergoing assisted reproduction. Am J Clin Nutr. 2016;104:729-735.

27. Lopes VM, Lopes JR, Brasileiro JP, Oliveira I, Lacerda RP, Andrade MR, Tierno NI, Souza RC, Motta LA. Highly prevalence of vitamin D deficiency among Brazilian women of reproductive age. Arch Endocrinol Metab. 2016;10.

28. Franasiak JM, Molinaro TA, Dubell EK, Scott KL, Ruiz AR, Forman EJ, Werner MD, Hong KH, Scott RT Jr. Vitamin D levels do not affect IVF outcomes following the transfer of euploid blastocysts. Am J Obstet Gynecol. 2015;212:315.e1-6

29. Evans KN, Nguyen L, Chan J, Innes BA, Bulmer JN, Kilby MD, Hewison M. Effects of 25-hydroxyvitamin D3 and 1,25-dihydroxyvitamin D3 on cytokine production by human decidual cells. Biol Reprod. 2006;75:816-822.

30. Blank M, Shoenfeld Y. Antiphospholipid antibody-mediated reproductive failure in antiphospholipid syndrome. Clin Rev Allergy Immunol. 2010;38:141-147.

31. Twig G, Shina A, Amital H, Shoenfeld Y. Pathogenesis of infertility and recurrent pregnancy loss in thyroid autoimmunity. J Autoimm. 2012;38:275-281.

32. Hidaka Y, Amino N, Iwatani Y, Kaneda T, Nasu M, Mitsuda N, et al. Increase in peripheral natural killer cell activity in patients with autoimmune thyroid disease. Autoimmunity. 1992;11:239-246.

33. Poppe K, Glinoer D, Van Steirteghem A, Tournaye H, Devroey P, Schiettecatte J, Velkeniers B. Thyroid dysfunction and autoimmunity in infertile women. Thyroid. 2002;12:997-1001.

34. Kachuei M, Jafari F, Kachuei A, Keshteli AH. Prevalence of autoimmune thyroiditis in patients with polycystic ovary syndrome. Arch Gynecol Obstet. 2012;285:853-856.

35. Ott J, Aust S, Kurz C, Nouri K, Wirth S, Huber JC, Mayerhofer K. Elevated antithyroid peroxidase antibodies indicating Hashimoto's thyroiditis are associated with the treatment response in infertile women with polycystic ovary syndrome. Fertil Steril. 2010;94:2895-2897.

36. Valensise H, Vaquero E, De Carolis C, Stipa E, Perricone R, Arduini D, Romanini C. Normal fetal growth in women with antiphospholipid syndrome treated with high-dose intravenous immunoglobulin (IVIG). Prenat Diagn. 1995;15:509-517.

37. Carp HJ, Shoenfeld Y. Anti-phospholipid antibodies and infertility. Clin Rev Allergy Immunol. 2007;32:159-161.

38. Perricone C, De Carolis C, Giacomelli R, Zaccari G, Cipriani P, Bizzi E, Perricone R. High levels of NK cells in the peripheral blood of patients affected with anti-phospholipid syndrome and recurrent spontaneous abortion: a potential new hypothesis. Rheumatology. 2007;46:1574-1578.

39. McIntyre JA. Antiphospholipid antibodies in implantation failures. Am J Reprod Immunol. 2003;49:221-229.

40. Costa M, Colia D. Treating infertility in autoimmune patients. Rheumatology (Oxford). 2008;47(Suppl 3):iii38-iii41.

41. Carp HJ, Meroni PL, Shoenfeld Y. Autoantibodies as predictors of pregnancy complications. Rheumatology (Oxford). 2008;47(Suppl 3):iii6-iii8.

42. Pasoto SG, Abrao MS, Viana VS, Bueno C, Leon EP, Bonfa E. Endometriosis and systemic lupus erythematosus:a comparative evaluation of clinicalmanifestations and serological autoimmune phenomena. Am J Reprod Immunol. 2005;53:85-93.

43. Moini A, Shirzad N, Ahmadzadeh M, Hosseini R, Hosseini L, Sadatmahalleh SJ. Comparison of 25-hydroxyvitamin D and Calcium Levels between Polycystic Ovarian Syndrome and Normal Women. Int J Fertil Steril. 2015;9:1-8.

44. Johnson LE, DeLuca HF. Vitamin D receptor null mutant mice fed high levels of calcium are fertile. J Nutr. 2001;131:1787-1791.

How to cite this article: Triggianese P, Watad A, Cedola F, et al. Vitamin D deficiency in an Italian cohort of infertile women. Am J Reprod Immunol. 2017;e12733.

https://doi.org/10.1111/aji.12733 